\title{
Lying on a test and in the laboratory
}

\author{
B. L. KINTZ \\ Western Washington State College, Bellingham, Washington 98225
}

\begin{abstract}
A lie scale was administered to college students. Three groups were formed according to the degree to which they responded truthfully to the statements. The subjects were then individually run in a visual perception task with dissyllables being presented for short time durations. Two response measures were taken: the latency of the first verbal response and the number of incorrect intrusions made during the experiment. The results showed that the liars responded with shorter latencies and made more intrusions than either of the other groups. There were no differences between the truthtellers and the medium group.
\end{abstract}

Examining children in the age range from 9 to 16 in 23 different schools, Hartshorne and May (1928) collected their data for the classic study of deceit. Defining deceit as: lying, cheating, or stealing, the authors concluded that: "neither deceit nor its opposite, "honesty," are unified character traits but rather specific functions of life situations. Most children will deceive in certain situations and not in others (p. 411)." A major thrust of the classic study was to establish useful techniques for detecting lying.

That people, at all ages, do tell lies in certain circumstances seems to be a widely accepted fact. The best methods for detecting lying has been an engaging problem for electronic equipment technologists and for certain persons associated mainly with crime detection. Lykken (1974) has pointed out that a major industry has grown up to provide lie detection machinery and technicians who claim to be able to detect deceivers, especially persons who steal merchandise. One problem associated with such detection is that the "expert" usually assumes that deceivers possess a common trait, viz, they are liars. This generalization goes counter to the conclusion drawn by Hartshorne and May with respect to children.

In an attempt to discover whether trained detectives could differentiate between people who lied and those who told the truth, Olechowski (1967) tape recorded interviews with young adults, 20 of whom lied and 20 of whom told the truth about themselves. The interviews were conducted in such a way that the lies presented an improved personal image of the liar. The tapes were then presented to 21 experienced detectives, 145 college-level psychology students, and 200 high school students. No group was very successful at detecting the liars, and none was better than the others. Also, there was no discernible pattern of vocal behavior that distinguished liars from truthtellers.

The present study was an attempt to explore some further components of lying. The basic question investigated was: "If persons lie in a questionnaire situation, will they exhibit some characteristic behavior different from nonliars, in a visual threshold detection situation?"

\section{QUESTIONNAIRE PROCEDURE}

A questionnaire containing 60 items similar to those used by Hartshorne and May was constructed. The items were statements about personal and social behavior about which there would be general public agreement as to their propriety. The statements were worded such that half of them would be answered "no" by most truthful people, and the other half would be answered "yes." Examples of "yes" questions are: (1) Did you ever accept the credit or honor for anything when you knew the credit or honor belonged to someone else? (2) Have you ever disobeyed any law of your country or any other rule? Examples of "no" questions are: (1) Do you always finish your work before you do other things? (2) Do you often give away anything which is very dear to you or which you have obtained at a sacrifice?

The questionnaire was administered to 63 college students. They were instructed to answer each question quickly, either "yes" or "no," and they were advised not to ponder the questions for any length of time before making a decision. The students were provided with IBM answer sheets and used the T-F spaces for their yes-no responses.

\section{QUESTIONNAIRE RESULTS}

The 60-item by 63-person matrix of responses was tabulated, and a Kuder-Richardson (or Nunnaly "alpha") coefficient was computed. The $\mathrm{r}$ value was .97 $\left(r^{2}=.94\right)$.

The 60 items were then separated into three groups of 20 each based upon the frequency with which the students responded "yes" to the item. The 20 low-frequency items thus represented those statements with which few people agreed (of the 63 persons tested, the number of "yes" responses ranged from 1 through 21). The high-frequency items were agreed with by many people (from 46 through 60 "yes" responses). And the medium frequency items were somewhat equivocally agreed with (from 22 through 44 ).

Liars were then defined as those persons who answered a high proportion of the questions in the 

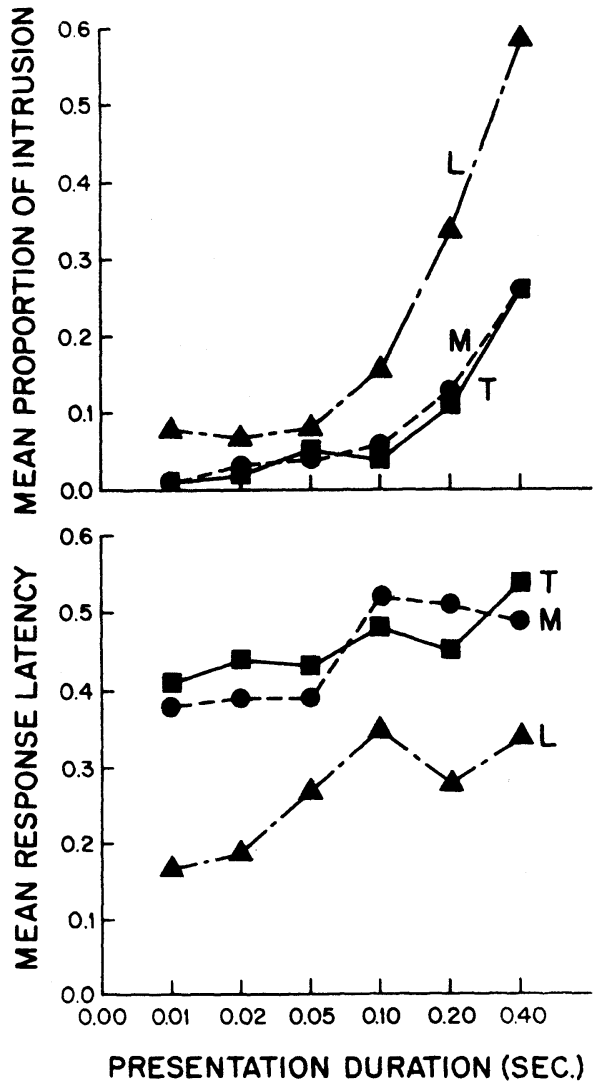

Figure 1. Intrusions and latencies as functions of experimental group and presentation duration.

unexpected manner (i.e., they often said "no" to the "yes" items and "yes" to the "no" items. Truthtellers were defined as those who answered most often in the expected manner. The middle group, of course, fell in between. By counting the respcnses made by each person relative to the above criteria, 23 liars and 21 truthtellers were quickly identified. The remaining 19 were consigned to the medium group. Three persons in the truthful group were later discovered to have actually been "yes" responders. By responding "yes" to nearly all statements, they scored high in agreement with the expected direction but were actually not reliably honest by the above definition. The data for those three were discarded, leaving 18 in the truthful group.

\section{VISUAL TASK PROCEDURE}

The 60 students were presented with the 96 dissyllables created by Noble (1952). A tachistoscope was used to present each dissyllable for six durations $(.01, .02, .04, .10, .20$, and $.40 \mathrm{sec})$. A modified ascending method of limits was employed. The stimuli were illuminated at approximately $.10 \mathrm{~mL}$. Solomon and Postman (1952) had found that most tachistoscopically presented words could be detected at from .14 to $.40 \mathrm{sec}$ duration. They did not mention the illumination used, but Hunter and Sigler (1940) had found that subjects could perceive several dots in a field within the range of .01 to $.40 \mathrm{sec}$ when the illumination was around $.1 \mathrm{~mL}$. These values were thus selected for pilot work in the present study and proved to be adequate.

Two response measures were recorded: (1) the latency of the first vocalization was measured using a voice-activated switch and a printout timer, and (2) the number of incorrect intrusions for each subject was recorded.

\section{VISUAL TASK RESULTS}

Few subjects responded at the fast presentations. Since only incorrect intrusions were recorded, correct responses were ignored. For each subject, there were 96 dissyllables presented for each of six different durations. The stimuli were presented as rapidly as the experimenter could work, and the typical experimental time for each subject was less than $30 \mathrm{~min}$.

When an intrusion was made, the fact was tallied, and the latency of the response was marked. The mean proportion of subjects in each group making intrusions was computed. For those subjects who responded, the mean latencies were computed. Both response measures are presented in Figure 1. As can be seen, the liars produced many more incorrect intrusions than the other groups. The liars also responded with shorter latencies.

Analyses of variance were computed for each set of data. A mixed two-variable ANOVA was used to analyze the intrusion data. The $F$ for groups is large $(F=5.13$, $\mathrm{df}=2 / 57, \mathrm{p}<.01$ ), showing that the liars made more intrusions than the others. The $\mathrm{F}$ for presentation time is large and self-explanatory $(F=7.76, d f=5 / 285$, $p<.01)$. The interaction $F$ is large because the liars actually produced proportionately more intrusions at the long presentation times than at the short times $(\mathrm{F}=2.34, \mathrm{df}=10 / 285, \mathrm{p}<.05)$.

Since the number of subjects intruding increased as the presentation time was increased, it was not possible to analyze the entire set of latency data in one design. Since the most important differences between liars and the other two groups occurred at the .20- and .40-sec presentation times, a separate randomized ANOVA was run at those two times. The groups differed in both cases (for $.2 \mathrm{sec}, \mathrm{F}=5.28, \mathrm{df}=2 / 44, \mathrm{p}<.01$; for $.4 \mathrm{sec}$, $\mathrm{F}=5.43$, df $=2 / 51, \mathrm{p}<.01)$. Further, $\mathrm{t}$ tests were run to explore these differences. The liars differed from the other two groups at both of the presentation times, but the medium group and the truthtellers did not differ [for $.20 \mathrm{sec}, \mathrm{t}$ for $\mathrm{L}-\mathrm{T}(44)=-2.98, \mathrm{~L}-\mathrm{M}(44)=-4.18$, $\mathrm{T}-\mathrm{M}(44)=-.97$; and for $.40 \mathrm{sec}, \mathrm{t}$ for $\mathrm{L}-\mathrm{T}(51)=-4.00$, $\mathrm{L} \cdot \mathrm{M}(51)=-3.06, \mathrm{~T} \cdot \mathrm{M}(51)=.91]$.

\section{DISCUSSION}

These results indicate that the questionnaire reliably detected a group of people who could logically be described as liars and other people who seem to be more truthful. Further, the liars 
reacted differently from the other two groups on a visual task when two different response measures were taken.

The obvious explanation for these results is that the liars were less inhibited about making intrusive errors. They responded even when they couldn't actually perceive the stimuli, and they responded with shorter latencies. It could be said that the liars, in trying to improve their image, guess (intrude) rather wildly. The truthtellers and medium group seem to represent more conservative persons who preferred to wait a bit until they were certain they correctly perceived the stimuli.

The degree to which the above comments serve some explanatory purpose probably depends somewhat upon the patterns of development of lying during childhood. Hartshorne and May reported that older children practiced deceit more, on the average, than did younger children. Observation and experience certainly suggest that children are presented with many opportunities for lying and that lying often tends to be reinforced. Parents and teachers typically teach that "honesty is the best policy," but children early learn that honesty may well be followed by punishment; whereas a timely lie, forthrightly told, results in smiles and good feelings.

No uselul theory attempting to explain lying exists. Doubtless, one reason is that truth seems to be an exceptionally ephemeral concept, seeming to be one thing at one time and a different thing later. In commenting about Carnap's (1942) "theories of truth," Cousin (1950) argues that truth ought to be regarded as a pragmatical concept rather than as an absolute or as a mere semantical ploy. As Cousin puts it, "Two speakers may use different sentences in making the same statement because they feel differently about the facts stated or because they are talking to persons whose feelings about them are different or because the respective audiences are differently equipped with knowledge relevant to the appreciation or even understanding of what is stated (p. 19)." And, as an explicit example, Cousin says, "It does not seem to me that the difference between saying "Queen Anne is dead" and saying "It's true that Queen Anne is dead" is really very like the difference between saying (1) "Queen Anne is dead." (2) "Alas! Queen Anne is dead." (3) "Hurrah! Queen Anne is dead (p. 19)."

\section{REFERENCES}

Carnap, R. Introduction to semantics. Cambridge, Massachusetts: Harvard University Press, 1942.

Cousin, D. R. Carnap's theories of truth. Mind, 1950, LVIV 1-22.

Hartshorne, H., \& May, M. A. Studies in deceit. New York: MacMillan, 1928.

Hunter, W. S., \& Sigler, M. The span of visual discrimination as a function of time and intensity of stimulation. Journal of Experimental Psy chology, 1940, 26, 160-179.

Lykken, D. T Psychology and the lie detector industry. American Psy chologist, 1974, 29, 725-739.

Noble, C. E. An analy sis of meaning. Psychological Review, $1952,59,421-430$

Olechowski, R. Experimente über den Stimm, und Sprechausdrück beim Lügen. (Experiments on voice modulation while telling lies.) Zeitschrift für experimentelle und ange wandte Psy chologie, 1967, 14, 474-482.

Solomon, R. L., \& Postman, L. Frequency of usage as a determinant of recognition threshold for words. Joumal of Experimental Psychology, 1952, 43, 195-201.

(Received for publication April 24, 1975.) 